\title{
Service Development for Behavioural Addictions: AIIMS Experience
}

\author{
Yatan Pal Singh Balhara, Rachna Bhargava, Rakesh K. Chadda \\ Behavioural Addictions Clinic (BAC), National Drug Dependence Treatment Center and \\ Department of Psychiatry, All India Institute of Medical Sciences, New Delhi.
}

\begin{abstract}
The concept of behavioural addiction is relatively new. The growing recognition of the behavioural addictions globally and increasing clinical queries catalysed the ongoing deliberations on setting up services for addressing behavioural addictions at the All India Institute of Medical Sciences (AIIMS), New Delhi. This led to establishment of what is arguably the first Behavioural Addictions Clinic (BAC) in the country. The clinic is an initiative of the Department of Psychiatry and National Drug Dependence Treatment Center (NDDTC), AIIMS, New Delhi. The current article offers an overview of the BAC, AIIMS, New Delhi.
\end{abstract}

Keywords: Behavioural addictions, internet addiction, internet gaming disorder, public health.

\section{Introduction}

Addictive disorders have been identified as significant contributors to the global burden of disease (1). These are not only associated with the adverse health consequences such as increased morbidity and mortality, but also impact the familial, social, occupational, financial and legal domains of life. The adverse consequences associated with addictive disorders extend beyond the individual to the family and community.

Traditionally, addictive disorders have largely been attributed to the use of psychoactive substances. In fact, the terms addictive disorders and substance use disorders have been used interchangeably in literature. A psychoactive substance is a chemical that acts upon the brain, resulting in changes in perception, mood, consciousness, cognition, and/or behaviour.
However, during the past two decades it has been increasingly realised that while certain addictive disorders are related to the use of psychoactive substances, there are other addictive disorders that do not include use of the psychoactive substances. These addictive disorders are known as behavioural addictions. Non-substance addictions, non-chemical addictions and process addictions are some other terms used to describe these conditions. Some of the commonly described and reported behavioural addictions in the literature include gambling disorder, internet gaming disorder, internet addiction and sexual addiction.

\section{Prevalence of Behavioural Addictions}

While the behavioural addictions have generated a considerable interest among researchers over the past few decades, there are only a few large-scale studies that have explored

Correspondence : Dr. Yatan Pal Singh Balhara, Associate Professor, Behavioural Addictions Clinic (BAC), National Drug Dependence Treatment Center and Department of Psychiatry, All India Institute of Medical Sciences, New Delhi-110029.Email: ypsbalhara@gmail.com. Mob: 9868976365. 
the prevalence of these conditions. There is a considerable variation in the reported prevalence of different behavioural addictions across studies. This difference in prevalence rates can be attributed to the differences in the study design, definition of behavioural addictions, diagnostic criteria, choice of screening instrument, and type of population studied among others. In an earlier report, the prevalence of adult gambling disorder has been found to vary from $0.1 \%$ to $2.7 \%$ (2). The proportion of persons with pathological gambling is relatively higher among college students (3). The prevalence of internet addiction among adolescents has been reported to vary from $4.0 \%$ to $19.1 \%$ (3). The reported range of internet addiction among adults is $0.7 \%$ to $18.3 \%$ (3). The prevalence rates for problematic video game playing among adolescents have been reported to vary from $4.2 \%$ to $20.0 \%$ across studies (3). There is limited literature on other behavioural addictions to make firm conclusions about their prevalence rates.

An Indian study in selected urban localities of Bengaluru reported prevalence rates of $1.3 \%$ for internet addiction (2\% males and $0.6 \%$ females) and $4.1 \%$ for mobile phone overuse (5\% males and $3.1 \%$ females)(4). A comparative study among medical students across three countries (including India) found $0.5 \%$ of the students to score in the range of severe problematic internet use (5). A recent survey among the attendees of a trade promotion event found that $15 \%$ of the respondents endorsed five or more features (out of nine) of behavioural addictions related to use of mobile technology (6). Most of the Indian studies on problematic internet use have focused on the students. Table 1 presents the summary of Indian studies that have explored prevalence of internet addiction/problematic internet use among students (7-26).

Table 1: Summary of the Indian studies that have explored internet addiction/ problematic internet use among students

\begin{tabular}{|c|c|c|c|}
\hline Authors & Year & Instruments & $\begin{array}{l}\text { Prevalence/Status of } \\
\text { Internet Addiction }\end{array}$ \\
\hline Meena et al (7) & 2012 & Young's Internet Addiction Test & $\begin{array}{l}59 \% \text { - average users } \\
25 \% \text { - occasional } \\
\text { problematic behaviour } \\
2 \% \text { - severe problems }\end{array}$ \\
\hline $\begin{array}{l}\text { Chathoth et al } \\
\text { (8) }\end{array}$ & 2013 & Young's Internet Addiction Test & $\begin{array}{l}58 \% \text { - mild } \\
19 \% \text { - moderate to severe }\end{array}$ \\
\hline Goel et al (9) & 2013 & $\begin{array}{l}\text { Young's Internet Addiction Test, } \\
\text { Duke Health Profile }\end{array}$ & $\begin{array}{l}75 \% \text { - moderate users } \\
25 \% \text { - possible addiction } \\
0.7 \% \text { - addiction }\end{array}$ \\
\hline Yadav et al (10) & 2013 & $\begin{array}{l}\text { Young's Internet Addiction Test, } \\
\text { 21-item Depression Anxiety \& } \\
\text { Stress Scale }\end{array}$ & $12 \%$ - addiction \\
\hline $\begin{array}{l}\text { Kawa and Shafi } \\
\text { (11) }\end{array}$ & 2015 & $\begin{array}{l}\text { Young's Internet Addiction Test } \\
\text { (IAT), Kessler Psychological } \\
\text { Distress Scale (K10) and } \\
\text { Demographic Data Sheet }\end{array}$ & $\begin{array}{l}67 \% \text { - mild } \\
29 \% \text { - moderate } \\
4 \% \text { - severe }\end{array}$ \\
\hline Jain et al (12) & 2014 & Young's Internet Addiction Test & $\begin{array}{l}8 \% \text { students overuse; } 1 \% \\
\text { were addicted }\end{array}$ \\
\hline
\end{tabular}




\begin{tabular}{|c|c|c|c|}
\hline $\begin{array}{l}\text { Kodvanji et al } \\
\text { (13) }\end{array}$ & 2014 & Young's Internet Addiction Test & $19 \%$ were addicted \\
\hline $\begin{array}{l}\text { Sharma et al } \\
\text { (14) }\end{array}$ & 2014 & Young's Internet Addiction Test & $\begin{array}{l}35 \% \text { - mild } \\
7 \% \text { - moderate } \\
0.3 \% \text { - severe }\end{array}$ \\
\hline $\begin{array}{l}\text { Srijampana et al } \\
(15)\end{array}$ & 2014 & Young's Internet Addiction Test & \begin{tabular}{|l|}
$2 \%$ - possible addiction \\
$0.4 \%$ - addiction \\
\end{tabular} \\
\hline $\begin{array}{l}\text { Vyjayanthi et al } \\
\text { (16) }\end{array}$ & 2014 & Young's Internet Addiction Test & $9 \%$ - total prevalence \\
\hline Balhara et al (5) & 2015 & Young's Internet Addiction Test & \begin{tabular}{|l|}
$9 \%$ - mild \\
$11 \%$ - moderate \\
$0.5 \%$ - severe \\
\end{tabular} \\
\hline $\begin{array}{l}\text { Chaudhari et al } \\
\text { (17) }\end{array}$ & 2015 & Young's Internet Addiction Test & $\begin{array}{l}51 \% \text { - mild } \\
7 \% \text { - moderate }\end{array}$ \\
\hline $\begin{array}{l}\text { Kakkar et al } \\
\text { (18) }\end{array}$ & 2015 & $\begin{array}{l}\text { Young's Internet Addiction Test, } \\
\text { Mental Health Battery }\end{array}$ & $\begin{array}{l}5 \% \text { students addicted with } \\
\text { significant problems }\end{array}$ \\
\hline $\begin{array}{l}\text { Krishnamurthy } \\
\text { and Chetlapalli } \\
\text { (19) }\end{array}$ & 2015 & Young's Internet Addiction Test & $\begin{array}{l}34 \% \text { - mild } \\
8 \% \text { - moderate }\end{array}$ \\
\hline Mitra et al (20) & 2015 & Young's Internet Addiction Test & $15 \%$ - problematic \\
\hline Setty et al (21) & 2015 & Young's Internet Addiction Test & $\begin{array}{l}75 \% \text { - moderate users } \\
25 \% \text { - possible addiction } \\
0.7 \% \text { - addiction }\end{array}$ \\
\hline $\begin{array}{l}\text { Sulania et al } \\
\text { (22) }\end{array}$ & 2015 & Young's Internet Addiction Test & $15.5 \%$ at high risk \\
\hline $\begin{array}{l}\text { Banjara and } \\
\text { Bhukya (23) }\end{array}$ & 2015 & Young's Internet Addiction Test & $\begin{array}{l}65 \% \text { - average users } \\
12 \% \text { - possible addiction } \\
2 \% \text { - addiction }\end{array}$ \\
\hline $\begin{array}{l}\text { Gedam et al } \\
\text { (24) }\end{array}$ & 2016 & $\begin{array}{l}\text { Young's Internet Addiction Test, } \\
\text { Mental Health Inventory }\end{array}$ & $\begin{array}{l}1 \% \text { - severe among medical } \\
\text { students } \\
2 \% \text { - severe among dental } \\
\text { students }\end{array}$ \\
\hline $\begin{array}{l}\text { Mahanty and } \\
\text { Mishra (25) }\end{array}$ & 2016 & $\begin{array}{l}\text { Problematic and Risky Internet } \\
\text { Use Screening Scale }\end{array}$ & $\begin{array}{l}70 \% \text { of students with mild } \\
\text { addiction }\end{array}$ \\
\hline Nath et al (26) & 2016 & Young's Internet Addiction Test & $\begin{array}{l}44 \% \text { - average users } \\
46 \% \text { - possible addiction } \\
0.5 \% \text { - addiction }\end{array}$ \\
\hline
\end{tabular}




\section{Nosological Journey}

The concept of behavioural addiction, while relatively new, has been documented for quite some time in the medical literature. Gambling disorder, one of the most well researched and described behavioural addictions, was first introduced in the 3rd Diagnostic and Statistical Manual (DSM-III) in 1980 (27). However, it was listed as pathological gambling under impulse control disorder. This was a reflection of the earlier conceptualization of pathological gambling as a disorder on impulsive-compulsive spectrum rather than being a clear addictive disorder. It was retained in DSM III R, DSM IV and DSM IV Text Revision (TR) as impulse control disorder (28). The International Statistical Classification of Diseases and Related Health Conditions (ICD10) also classified pathological gambling as a habit and impulse disorder.

However, the growing body of research over the past two decades fuelled the emerging consensus that pathological gambling is closer to the addictive disorder. The behavioural addictions have made a formal debut in the most recent version of 5 th edition of Diagnostic and Statistical Manual, i.e. DSM 5 (29). In fact, the DSM 5 has witnessed a paradigm shift with relabelling of the category of 'substance-related disorders' as 'substance-related and addictive disorders'. Gambling disorder is the first disorder to be listed as a behavioural addiction under this category. The upcoming revision of ICD, i.e. ICD 11 is also likely to follow the suit and introduce the behavioural addictions (30). Lack of sufficient peer reviewed evidence on other behavioural addictions has been cited as the only reason for their non-inclusion in DSM 5.

\section{Behavioural Addictions: Proximity to Substance Use Disorders}

The current conceptualisation of behaviour addictions groups these disorders closer to psychoactive substance use related addictions. Research studies have found multiple commonalties between these two sets of disorders. The co-occurrence rate of behavioural addictions and psychoactive substance use related addictions has been found to be high in clinical as well as epidemiological studies (31-33). Rapid reward discounting, poor performance on decision-making tasks, and diminished performance on tests of inhibition, cognitive flexibility, and planning tasks are cognitive deficits shared by persons with behavioural addictions as well as psychoactive substance use related addictions (2). Neurobiological studies have implicated similar brain regions (e.g. reward pathway, dorsolateral prefrontal cortex) and neurotransmitters and related enzymes (e.g. dopamine levels, platelet monoamine oxidase B activity) in emergence of both behavioural addictions and psychoactive substance use related addictions. Also, genetic studies have reported higher rates of substance use disorders among first degree relatives of persons with behavioural addictions. Finally, similar treatment approaches (pharmacological as well as non-pharmacological) have been found to be beneficial for the two sets of disorders (2).

Despite these similarities, behavioural addictions differ from psychoactive substance use related addictions on multiple accounts. Many of the bio-psycho-social underpinning related to behavioural addictions still remains largely unexplored. It is likely that despite of many commonalities between behavioural addictions and psychoactive substance use related addictions, it shall be too simplistic to see the two as a unitary concept. A better understanding of behavioural addictions consequent to ongoing research should help settle this debate in future.

\section{Management of Behavioural Addictions}

The research on management of behavioural addictions is still in its infancy. However, there is published evidence that can be used to guide clinical management of these disorders. It is recommended to follow an 
integrated approach that includes a mix of pharmacological and non-pharmacological interventions. The medicines that have been found to be effective in management of behavioural addictions have been summarised in Table 2.

Table 2: Pharmacological interventions found effective in management of behavioural addictions

\begin{tabular}{|l|l|}
\hline Medicine & Type of study \\
\hline Naltrexone & Double blind placebo controlled trials \\
\hline Nalmefene & Double blind placebo controlled trials \\
\hline Fluvoxamine & Double blind placebo controlled trials \\
\hline Paroxetine & Double blind placebo controlled trials \\
\hline Lithium & Double blind placebo controlled trials \\
\hline Escitalopram & Open label trials/ case reports \\
\hline N-Acetyl cysteine & Open label trials/ case reports \\
\hline Memantine & Open label trials/ case reports \\
\hline Amantadine & Open label trials/ case reports \\
\hline Acamprosate & Open label trials/ case reports \\
\hline
\end{tabular}

The non-pharmacological interventions that have been explored for management of behavioural addictions include cognitive behaviour therapy, behaviour therapy, time management skills, solution focused brief therapy, and a combination of group and individual therapies. A meta-analysis on effectiveness of treatment modalities for internet addiction found psychological as well as pharmacological treatment to be beneficial in management of internet addiction (34). Indian Psychiatric Society has in recent past published guidelines on management of behavioural addictions (35). It is also important to identify and manage the co-occurring mental disorders and substance use related disorders among persons with behavioural addictions.

\section{Addressing Behavioural Addictions in the Country: the AIIMS Initiative}

The growing recognition of the behavioural addictions globally and increasing clinical queries catalysed the ongoing deliberations on setting up services for addressing behavioural addictions at the All India Institute of Medical Sciences (AIIMS),
New Delhi. This led to establishment of what is arguably the first Behavioural Addictions Clinic (BAC) in the country that is aimed at addressing all types of behavioural addictions. While initiatives taken so far in this area have targeted a particular type of behavioural addiction, the BAC at AIIMS caters to all types of nonsubstance use-related addictive disorders. The clinic is an initiative of the Department of Psychiatry and National Drug Dependence Treatment Center (NDDTC), AIIMS, New Delhi.

The BAC is housed in the Department of Psychiatry at AIIMS, New Delhi. It is a weekly clinic, that is held in the out-patient setting on every working Saturday. The clinic is run by a team of mental health professionals that include faculty from psychiatry and clinical psychology. The clinic has witnessed a gradual but steadily increasing clinical consultations since its inception. The clinic offers comprehensive screening, assessment and management services for behavioural addictions. Another emphasis at the clinic is for assessment and management of co-occurring mental and substance use disorders among those with behavioural addictions. 
The most commonly observed behavioural themes include excessive and problematic use of internet, social media platforms, internet-based games, online pornography and gambling. Almost all the cases presenting to us have experienced significant socio-occupational dysfunction. In fact, emergence of this dysfunction is the most important reason for help seeking. Some of the commonly observed dysfunctions include declining academic performance, discontinuation of studies, financial losses, and interpersonal conflicts. Presence of co-occurring mental and substance use disorders is another significant findings among these cases. While a few persons seek help on their own, majority attend the clinic on insistence and persuasion of care givers. They are mostly young school-/ college-going adolescents who actively deny their internet/smartphone use as problematic or having addiction. However, majority of the patients are male youth with age ranging between 16 and 25 years. The clinic has also witnessed consultation concerning the controversial 'Blue Whale Challenge'.

Apart from setting up clinical service, the BAC has also taken certain public health initiatives on the behavioural addictions. These include a collaboration with South East District Delhi Police to spread awareness on safe and healthy use of internet. The BAC, AIIMS is a collaborating partner of Delhi Police in this initiative targeted at the school students. Also, the BAC has contributed to the media reports on behavioural addictions aimed at increasing awareness among general public about this issue and spreading the information about the availability of such services. Additionally, the BAC has also participated in screening camps in collaboration with other medical institutes, where the visitors of the camp have been screened for presence of behavioural addictions related to use of mobile technology. Apart from this, contributions were made to the first ever consultative meeting on public health implications of excessive use of the internet, computers, smart phones and similar electronic devices organised by the World Health Organization (WHO) (36).

The BAC is also engaged in carrying out research activities on the themes related to behavioural addictions. While some of these projects have been completed others are underway. The findings from these studies have been published in peer reviewed academic journals $(5,6,37)$. The clinic proposes to conduct studies on prevalence, bio-psychosocial correlates, and awareness and attitude towards the behavioural addictions. This is in keeping with the current conceptualisation of behavioural disorders as having bio-psychosocial underpinnings.

\section{Way Ahead}

The BAC at AIIMS recognises and realizes that behavioural addictions are a growing problem of public health importance. There is a need to spread awareness on presence of the problem as well as existing services for taking care of the same. The BAC aims to extend the public health campaign to a wider section of population. Also, it aims to expand research on various domains of these disorders. The clinic also aims to bring out recommendations and guidelines on prevention, screening, assessment and management of behavioural addictions. Presently, the BAC is well prepared and well placed to assume the leadership role in this area with contribution and participation of various stakeholders.

\section{References}

1. Whiteford HA, Degenhardt L, Rehm J, et al (2013). Global burden of disease attributable to mental and substance use disorders: findings from the Global Burden of Disease Study 2010. Lancet 382:1575-1586.

2. Lorains FK, Cowlishaw S, Thomas SA (2011). Prevalence of comorbid disorders in problem and pathological gambling: 
systematic review and meta-analysis of population surveys. Addiction 106(3):490-498.

3. Yau YH, Potenza MN (2015). Gambling disorder and other behavioral addictions: recognition and treatment. Harv Rev Psychiatry 23(2):134-146.

4. Sharma M, Benegal V, Rao G, Thennarasu K (2013). Behavioral Addiction in the Community: An Exploration. A Research Project Report submitted to the Indian Council of Medical Research, New Delhi in 2013.

5. Balhara YPS, Gupta R, Atilola O, et al (2015). Problematic internet use and its correlates among students from three medical schools across three countries. Acad Psychiatry 39(6):634-638.

6. Balhara YPS, Dahiya N, Varshney M, Garg S, Bhargava R (2018). Awareness, self-assessment and help seeking behavior for behavioral addictions related to use of mobile technology among attendees of a health camp. J Assoc Physicians India $\mathbf{6 6}$ :48-51 (in print).

7. Meena PS, Mittal PK, Solanki RK (2012). Problematic use of social networking sites among urban school going teenagers. Indian Psychiatry J 21(2):94-97.

8. Chathoth V, Kodavanji B, Arunkumar N, Pai S (2013). Internet behaviour pattern in undergraduate medical students in Mangalore. Int $J$ Innovative Res Sci Engineering Technol 2(6):2133-2136.

9. Goel D, Subramanyam A, Kamath R (2013). A study on the prevalence of internet addiction and its association with psychopathology in Indian adolescents. Indian J Psychiatry 55(2):140-143.

10. Yadav P, Banwari G, Parmar C, Maniar R
(2013). Internet addiction and its correlates among high school students: a preliminary study from Ahmedabad, India. Asian J Psychiatr 6(6):500-505.

11. Kawa M, Shafi H (2015). Evaluation of internet addiction and psychological distress among university students. Int $J$ Modern Soc Sci 4(1):29-41.

12. Jain T, Mohan Y, Surekha S, et al (2014). Prevalence of internet overuse among undergraduate students of a private university in South India. Int $J$ Recent Trends Sci Technol 11(3):301-304.

13. Kodavanji B, Chathoth V, Kumar N, Anupama N, Pai S (2014). Impact of internet use on lifestyle in undergraduate medical students. Cancer Res Oncol 1 :187-189.

14. Sharma A, Sahu R, Kasar P, Sharma R (2014). Internet addiction among professional courses students: a study from central India. Int $J$ Med Sci Public Health 3(9):1069-1073.

15. Srijampana V, Endreddy A, Prabhath K, Rajana B (2014). Prevalence and patterns of internet addiction among medical students. Med J DY Patil Univ 7(6) :709713.

16. Vyjayanthi S, Makharam S, Afraz M, Gajrekar S (2014). Gender differences in the prevalence and features of internet addiction among Indian college students. Medica Innovatica 3(2):65-70.

17. Chaudhari B, Menon P, Saldanha D, Tewari A, Bhattacharya L (2015). Internet addiction and its determinants among medical students. Indian Psychiatry $J$ 24(2):158-162.

18. Kakkar N, Ahuja J, Dahiya P (2015). Influence of internet addiction on the 
academic performance and mental health of college students. Scholarly Res J Interdisciplinary Studies 3(21):11511161.

19. Krishnamurthy S, Chetlapalli S (2015). Internet addiction: prevalence and risk factors: a cross-sectional study among college students in Bengaluru, the Silicon Valley of India. Indian J Public Health 59(2):115-121.

20. Mitra A, Willyard J, Platt C, Parsons M (2005). Exploring web usage and selection criteria among male and female students. $J$ Computer-mediated Communication 10(3).

21. Setty S, Sudha K, Usha V (2015). A cross sectional study of internet addiction in undergraduate medical students. $J$ Dental Med Sci 14(12):108-111.

22. Sulania A, Sachdeva S, Dwivedi N (2015). Risk of internet addiction among undergraduate medical, nursing, and lab technology students of a health institution from Delhi, India. Digit Med 1 :72-78.

23. Banjara SK, Bhukya K (2015). The role of internet and its addiction among medical students in a tertiary care teaching hospital. Global $J$ for Res Analysis 1(8):316-317.

24. Gedam SR, Shivji IA, Goyal A, Modi L, Ghosh S (2016). Comparison of internet addiction, pattern and psychopathology between medical and dental students. Asian J Psychiatr 22:105-110.

25. Mahanty B, Mishra G( $\left.\begin{array}{llll}2 & 0 & 1 & 6\end{array}\right)$. Internet addiction and its psychological problems among nursing students of HiTech College of Nursing, Bhubaneswar, Odisha, India. Int $J$ Advanced Multidisciplinary Res 3(1):41-45.
26. Nath K, Naskar S, Victor R (2016). A cross-sectional study on the prevalence, risk factors, and ill effects of internet addiction among medical students in Northeastern India. Prim Care Companion CNS Disord 18(2). doi: 10.4088/PCC.15m01909. eCollection 2016.

27. American Psychiatric Association (1980). Diagnostic and Statistical Manual of Mental Disorders. Washington, DC: American Psychiatric Association.

28. American Psychiatric Association (2000). Diagnostic and Statistical Manual of Mental Disorders, DSM-IV-TR, Fourth Edition, (Text Revision). Washington, DC: American Psychiatric Association.

29. American Psychiatric Association (2013). Diagnostic and Statistical Manual of Mental Disorders (DSM-5). Washington, DC: American Psychiatric Publishing.

30. Grant JE, Atmaca M, Fineberg NA, et al (2014). Impulse control disorders and "behavioural addictions" in the ICD-11. World Psychiatr 13(2): 125-127.

31. Cunningham-Williams RM, Cottler LB, Compton WM, 3rd, Spitznagel EL (1998). Taking chances: problem gamblers and mental health disorders--results from the St. Louis Epidemiologic Catchment Area Study. Am J Public Health 88(7):10931096.

32. Petry NM, Stinson FS, Grant BF (2005). Comorbidity of DSM-IV pathological gambling and other psychiatric disorders: results from the National Epidemiologic Survey on Alcohol and Related Conditions. J Clin Psychiatry 66(5):564574.

33. Yen JY, Ko CH, Yen CF, Chen CS, Chen CC (2009). The association between 
harmful alcohol use and internet addiction among college students: comparison of personality. Psychiatry Clin Neurosci 63(2):218-224.

34. Winkler A, Dorsing B, Rief W, Shen Y, Glombiewski JA (2013). Treatment of internet addiction: a meta-analysis. Clin Psychol Rev 33(2):317-329.

35. Basu D, Dalal PK, Balhara YPS (2016). Clinical practice guidelines on newer and emerging addictive disorders in India: Overview of IPS guidelines 2016 (Editorial). In: Clinical Practice Guidelines on Newer and Emerging Addictive Disorders in India, 1st edn. Basu D, Dalal PK, Balhara YPS, eds. New Delhi: Indian Psychiatric Society.
36. Ray R, Sharma M, Balhara YPS (2014). Internet and Smartphone Addiction: Public Health Implications in Indian Context, Report No.: 9789241509367. Geneva, Switzerland: World Health Organization.

37. Sarkar S, Balhara YPS, Parmar A, Rajhans P (2017). A study of pathological gambling and its correlates among patients seeking treatment for substance use disorders in North India. $J$ Substance Use 23(2):193-198. 